\title{
Face-threatening talk on the factory floor: Using authentic workplace interactions in language teaching ${ }^{1}$
}

JONATHAN NEWTON - Victoria University of Wellington

\begin{abstract}
In this paper I examine a small set of authentic workplace interactions and explore the value of such material for ESOL/communication training for the workplace. The interactions consist of three episodes of face-threatening talk by members of a factory-floor team. The paper discusses the way this team constructed and managed politeness and solidarity in face-to-face interaction. In the team, politeness norms are 'honoured in the breech'. Ostensibly facethreatening talk conveys core in-group membership and appears to mitigate rather than boost the severity of face-threatening speech acts, thus reflecting the ways in which forms of talk are constructed within particular workplace contexts to produce diverse and localised communicative practices. In order to assist learners to acquire a broader repertoire of communication strategies with which to manage this kind of localised practice, a pedagogic response is presented involving three types of tasks: awareness-raising tasks, interpretation tasks and communication practice tasks.
\end{abstract}

\section{Authentic materials in language instruction}

This paper discusses the value of using recordings of authentic factory-floor interactions for instruction in intercultural communication for the workplace. Debate surrounds the notion of 'authenticity' and the value of exposing learners to authentic or natural language. The lack of ease around the issue is captured in a recent article title, 'Authentic materials, a wolf in sheep's clothing' (Day 2003). The debate is wide-ranging, encompassing areas such as: the nature of authenticity (Widdowson 1978; Breen 1985); authenticity in EAP/ESP contexts (MacDonald, Badger and White 2000); the role of corpora of authentic language in materials design and curricula (Cook 1997; Carter 1998; Kennedy 2003), for example, the COBUILD project (Sinclair 1987); the value of simplification and simplified materials for reading instruction (Nation and Wang 1999); and classroom uses of authentic material (Burns, Gollin and Joyce 1997; and detractors, Cook 1997; Day 2003).

Among those who argue the case for authentic materials, Burns, Gollin 
and Joyce (1997) claim that authentic spoken texts provide an important link to interaction outside the classroom and prepare students for the unpredictability of everyday communication. Carter (1998) uses corpus data to show how frequently occurring features of authentic conversation - such as three-part exchanges, vague language, ellipsis, hedging, widespread use of discourse markers, and interruptions - are absent from scripted dialogues in published ELT materials.

Arguing against authentic materials, Day (2003) claims that such materials are too difficult for many typical language students and so have a damaging effect on motivation and attitude. Cook (1997) challenges the need for authenticity by suggesting that the classroom is a 'play world in which people can practice and prepare' and not 'a real world where behaviour has serious consequences' (Cook 1997: 230).

In workplace contexts, practical problems restrict opportunities to obtain authentic workplace interactions: worksites are difficult to access for recording purposes; ethical matters and confidentiality create hurdles; expensive equipment is required; and recording and transcribing spoken data is difficult and time consuming. It is not surprising then that authentic workplace interactions are not commonly used as a resource in instructional materials, just as they are under-represented in interlanguage pragmatics (Kasper and Dahl 1991). Even when such obstacles are overcome, the data are typically messy and highly situated.

In the case of factory settings even more problems present themselves, and this has limited the number of studies using recordings of factory-floor data. Background noise is often present and intrusive, workers are frequently moving around, recording and recording equipment may compromise worker safety, and talk is not an obvious part of factory-floor work, which often involves workers in extended periods of solitary or silent work (Clyne 1994). However, literacy issues mean that spoken interaction is the primary channel of communication for many workers in this work context, although written and electronic documentation of various kinds is also an essential component of the production process (Stubbe 2000).

Fortunately, for the purposes of this study, a large corpus of transcribed and tagged recordings of workplace language was made available from the Language in the Workplace Project (LWP) at Victoria University of Wellington (Stubbe 2001). ${ }^{2}$ These data provided a unique opportunity to explore the value of authentic workplace talk for second language instruction.

\section{The factory floor}

While the corpus included data from both white- and blue-collar worksites, 
this paper focuses on a subset of the data recorded in factory-floor settings. The factory floor has not always received as much attention in the sociopragmatic literature as other workplace settings, such as service encounters (Leidner 1993; Cook-Gumperz 1994) and middle-class, professional/whitecollar settings (Willing 1992). Clyne (1994), Sunaoshi (1999) and Stubbe (2000) are notable exceptions.

The study took place in New Zealand where around 20 per cent of the workforce, and 13 per cent of workers in factory-floor settings, are from a non-English-speaking background. ${ }^{3}$ Such workers often face the challenge of not only working in a new language environment, but also navigating unfamiliar discourse conventions that arise from language systems based on different cultural values. Roberts (1999) analysed the English language needs of New Zealand factory workers and identified a priority need for training in communicative skills and pragmatic competence. Similarly, Clyne (1994), in a study of intercultural communication in Australian factory-floor settings, concluded that inter-cultural communication breakdown in our corpus ... is generally due to pragmatic and discourse issues, and not to matters of morphosyntax, phonology or the lexicon' (Clyne 1994: 204). In a number of factories associated with the project, workplace-based language and communication training is provided for employees from non-English-speaking backgrounds to meet this need.

\section{Face-threatening speech acts and politeness theory}

This paper focuses on face-threatening speech acts such as complaints, requests/refusals, directives and disagreements. Such speech acts are particularly problematic in intercultural communication; face needs are constructed differently across cultures, just as culture shapes the strategic and linguistic realisations of politeness (Brown and Levinson 1987; Blum-Kulka, House and Kasper 1989; Kasper and Blum-Kulka 1993; Trosberg 1995; Gass and Neu 1996; Kasper and Rose 2002).

Politeness theory as proposed by Brown and Levinson (1987) provides one perspective on face work and face-threatening acts. While this theory has received extensive criticism since it was first proposed (see Eelen 2001; Holmes and Stubbe 2003), it nonetheless continues to provide a useful framework for the analysis of discourse involving face-threatening acts such as complaints and refusals. Politeness is defined as behaviour which takes into account a person's 'face needs', a concept deriving from the work of Goffman (1967) and developed by Brown and Levinson (1987). While the term 'face' is based on the everyday usages 'losing face' and 'saving face', it 
goes further in treating almost every action (including utterances) as a potential threat to someone's face that is a face-threatening act (FTA).

According to Brown and Levinson's (1987) theory, politeness involves showing concern for two different kinds of face needs: firstly, negative face needs, or the need for privacy and distance from others; and secondly, positive face needs, the need to be approved of, liked and admired. Behaviour which avoids imposing on others (or avoids 'threatening their face') is described as evidence of negative politeness, while sociable behaviour expressing warmth towards an addressee is classified as positive politeness behaviour.

Politeness theory argues that the weight of a face-threatening act can be assessed with reference to three variables: the relative power between speaker and addressee $(\mathrm{P})$, the relative social distance between speaker and addressee (D), and the ranking or degree of imposition represented by the relevant speech act (R). Since the values of these factors are typically influenced by a range of contextual and cultural factors, politeness theory cannot provide precise predictions about the weighting of a particular FTA, nor predict the specific linguistic strategies to deal with it. It can, however, make general predictions about the relationship between the relative weighting of a FTA and the number and kind of linguistic strategies adopted to perform it politely. So, for example, it seems reasonable to expect that in most contexts a heavily weighted FTA will not be performed 'bald on record', but rather will be expressed using a range of linguistic politeness strategies. In this paper, I explore this idea in relation to a small sample of face-threatening speech episodes recorded in our workplace data.

\section{Methodology}

The current study is a small part of the Language in the Workplace Research Project at Victoria University of Wellington and draws its data from a large corpus of LWP recordings. These recordings were collected using a collaborative methodology whereby participants had maximal control over data collection. Follow-up interviews were carried out with participants and extensive workplace observations took place (Holmes and Stubbe 2003).

\section{PARTICIPANTS AND WORKSITE}

The interactions analysed for this paper were from a close-knit production team which had 22 core members, 16 of whom were male, with more than 50 per cent of the team of Maori or Pacific ethnicity. The official language of communication in the factory is English, but the workforce is multicultural and includes many people for whom English is a second language. It is 
not uncommon for other languages, such as Samoan and Tongan, to be used in work contexts between native speakers of these languages.

Talk is not the primary currency of work as it frequently is in the office workplace. Rather, talk is regarded predominantly as a means to a practical end. Communication on the factory floor is often sporadic, and predominantly involves the routine imparting of specific information or instructions, along with a certain amount of social talk, punctuated by episodes of 'troubleshooting' or problem-solving talk.

\section{DATA COLLECTION AND ANALYSIS}

More than 35 hours of recordings from our focus team have been transcribed to date. In order to identify key face-threatening speech episodes we approached the data through a process of interactive readings by which the researchers searched and coded speech episodes in a series of re-readings and comparisons. This process produced a corpus of 38 complaint and 15 request/refusal episodes, and a number of other face-threatening speech episodes. Three of these episodes have been chosen for close analysis in this paper. All names in the transcripts are pseudonyms. Participants in the selected examples were also involved in many of the examples not chosen, and, as verified through participant observation, the topics and language used are typical of the larger pool of speech events.

\section{Analysis: three face-threatening speech episodes}

The three episodes chosen for discussion consist of a complaint, a refusal and a directive. Each episode is presented below with a commentary examining the face work in the interaction.

\section{EPISODE I: COMPLAINT ${ }^{4}$}

Direct complaints (Boxer 1993) threaten both the positive and negative face of the addressee. Firstly, by stating or implying that they are responsible for a perceived offence, the complainer is threatening the addressee's positive face, their need to be approved of and liked. Secondly, by seeking redress the complainer impinges on the addressee's negative face, their need not to be imposed on. Politeness theory suggests that in order to ameliorate the impact of a FTA, the speaker will use negative politeness strategies such as hedging or indirectness, and positive politeness strategies which emphasise friendliness and solidarity.

The complaints in our data did not conform to this expectation. Instead, they were typically direct and laced with expletives, insults, accusations and criticisms. The complaint below is a typical example. In this direct complaint, 
Russell, a Samoan/European male packer aged 25-29, is complaining to Lesia, a Samoan male aged 30-34, who has some responsibility for the team's rosters. Russell is complaining that he has been on the same packing line for a long time. We would expect Russell to use a conventional politeness strategy to reduce the impact of his complaint, and redress the implied threat to Lesia's positive face. And yet by using ' $\mathrm{f}$ ***', Russell seems to increase the impact. Similarly, Lesia responds not with an apology or excuse as politeness theory predicts, but with criticism and an expletive.

\section{EPISODE I}

\section{Participants:}

Lesia: Samoan male aged 30-34

Russell: $\quad$ Samoan/European male aged 25-29

Russell: $\quad \mathrm{f}^{* * *}$ ing sick of this line (Lesia)

Lesia: $\quad[\mathrm{voc}]$

Russell: (stuck here) all the time

Lesia: $\quad$ if (you) i put you on that line you're getting worse

Russell: ( )

Lesia: $\quad \mathrm{f}^{* * *}$ ing worse + slow like an old man (all you have to teach) ++

Russell: (that's what i want) +++

Lesia: $\quad$ if $i$ put you on that line you falling asleep (6)

Russell: $\quad$ how much do we have to do on here (all day out)

Holmes and Stubbe (2003) describe the discourse practices of this team as demonstrating a very distinctive, sparky communicative style which has a strong orientation towards team morale. The team has a well-deserved reputation at the factory for uninhibited swearing and constantly joking around and 'having each other on', which sits alongside their status as the top-performing team. These kinds of playful yet highly competitive and 'in your face' strategies for building solidarity are well documented in all-male groups (for example, Kuiper 1991; Coates 1996; Kiesling 2001). Similarly, in the data discussed here, I interpret the use of expletives as building solidarity and conveying positive politeness.

\section{EPISODE 2: REFUSAL}

Refusals in authentic data typically involve lengthy negotiations and face-saving strategies to accommodate the non-compliant nature of the speech act (Houck and Gass 1996: 49). By rejecting a request, a refuser is presenting a threat to the requester's self-image. To resolve this problem, the refuser is 
likely to include linguistic elements such as hedges, which mitigate the refusal, and positive politeness strategies to support the face needs of the requester and acknowledge the legitimacy of the request (Besson, Roloff and Paulson 1998).

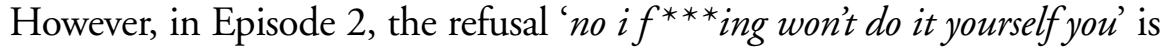
expressed baldly, on record and strengthened with an expletive and directive. Again our interpretation is that expletives here perform a solidarity function and reverse normative politeness patterns. By flouting the rules and using high levels of face-threatening talk, interlocutors appear paradoxically, from a conventional standpoint, to mitigate rather than boost the severity of a FTA. Such talk plays out a kind of parody.

\section{EPISODE 2}

\section{Participants:}

Ginette: $\quad$ Pacific Island female aged 30-34

M \& M2: $\quad$ Unidentified males

M2: [over the radio]: yeah Bert bro check our pallet downstairs for us please bro:

M: no if f** $^{* *}$ ing won't do it yourself /you tight bastard

Ginette: /[laughs]\[laughs] ++ see if he clicks on it's you

\section{EPISODE 3: DIRECTIVE}

In this episode the tone is rather more serious and face work takes more effort. Ginette, the supervisor, is giving Russell and others instructions on how to stack boxes correctly. Ginette issues a directive as a bald, on-record imperative, 'stack them properly'. When the workers respond with disclaimers, 'I always stack back on', and, 'you're assuming, eh, assuming bullshit', Ginette makes her intentions even more explicit by stating 'that was a instruction'. The response is further avoidance. Ginette then challenges the logic of their denials by asking 'if I come in and they're all on the wrong way on the pallet does that mean they're stacked properly?'. There is clearly only one answer to this question, but by giving this answer the workers would be implicating themselves and admitting responsibility for the problem. Instead, by responding with the sarcastic comment 'Beautiful', Simon avoids both a direct admission of responsibility and a direct challenge to Ginette's face. Although this sarcasm is impolite, it appears to be doing important face work.

Ginette is similarly indirect in her reply by responding with an insult, 'eh bloody Mäori I don't know'. Like the workers, Ginette's strategy allows her to express her frustration but without confrontation. In other contexts, an ethnic slur such as this would be inflammatory. Even if she has not received 
the agreement that her question sought, she has made her point. Instead of pushing further Ginette relents and responds with rueful frustration. Her message has been conveyed with a simultaneous tussle for face involving face-threatening and face-saving work by both parties, but not in ways that the literature, based predominantly on white middle-class usage, might lead us to expect.

\section{EPISODE 3}

\section{Participants:}

Ginette: $\quad$ Pacific Island female aged 30-34

Russell: $\quad$ Samoan/European male aged 25-29

Simon: $\quad$ Maori male aged 30-34

X: Unidentified speaker

Ginette: when yous take them off stack them properly

$\mathrm{X}$ : $\quad$ oh /(so who was) $\backslash$ taking them off from here and loading it

Russell: /it was ([name])।

Russell: $\quad$ (i always /stackl back on) +

X: $\quad$ /shamel

Simon: (you're assuming eh assuming bullshit eh)

Ginette: no i said what did i say + i said when you take them off stack them properly that wasn't an a assumption /that was al

Simon: /you assumed thatl somebody was not /stacking it properlyl

Ginette: /that was al instruction

Simon: you were assuming that someone has not taken it off but not /()।

Ginette: $\quad /$ so $\backslash$ if $\mathrm{i}$ come and they're in a big heap $/+\mid$ they're stacked properly?

Simon: /whatl

Simon: if you what

Ginette: if $\mathrm{i}$ come in and they're all on the wrong way on the pallet does that mean they're stacked properly

Simon: beautiful

Ginette: bloody [drawls]: /beautiful:।

Simon: $\quad /()$

Ginette: eh bloody maöri i don't know

The three episodes that I have discussed are characterised by bald, onrecord speech acts and accompanied by expletives and jocular abuse. Such stylistic features, when used with ostensibly face-threatening speech acts, typically boost threat to face. However, in the context of this factory team, I would argue that such talk is doing positive face work by marking out 
membership of the team and distinguishing a community of practice (Holmes and Meyerhoff 1999). Flouting the rules during in-group interactions qualifies as a positive politeness strategy, constructing solidarity and reinforcing team membership. By contrast, the same kinds of speech acts with people outside of the group tend to be longer, more indirect and include only mild expletives, if any (Daly et al in press). In effect, the episodes discussed above convey the message that 'I can talk to you like this because I know you so well. Our talk constructs and maintains our membership as part of a group which we are proud to belong to.'

This interpretation is consistent with a number of studies into jocular abuse. Hay (1994), for example, showed that jocular abuse was a strategy used to express group membership and solidarity in regular meetings of a role-playing group. Kuiper (1991) reports similar findings in a study of sexual humiliation in the locker room after a rugby game. Likewise, Hughes (1992) in a study of expletives within a closely knit group of British lower working-class women notes that their extensive use of expletives '.. is in keeping with a toughness that is necessary in their lives and that is a part of the social bonding in their group' (Hughes 1992: 300).

In sum, these three episodes reveal features of authentic and situated talk that are generally (and not surprisingly) underplayed in ESOL workplace training materials. In the next section, options for using these data in instructional materials are discussed.

\section{Implications for instruction}

In planning this study I expected the face-threatening speech acts that we collected to provide a resource bank of politeness strategies, including mitigation strategies, softening devices and indirect forms. I was startled by the paucity of conventional politeness strategies in the data, and puzzled by the problem of how to harness such data for the language classroom. Quite apart from the question of whether it is appropriate to introduce strong expletives into the classroom, little usable material emerged that could exemplify effective ways to manage the face-threatening dimensions of factory-floor talk.

However, on second thoughts, two responses to the data seemed possible. First, if indeed new migrant workers are to encounter talk of this nature outside the classroom, they will benefit from opportunities to meet it first in training materials. The goal is not language production, but awareness raising and rehearsing the skill of interpreting discourse in context. It is worth noting that the episodes discussed above represent talk between insiders, between established members of this community of practice. Talk with outsiders 
conforms much more closely to conventional notions of politeness and appropriateness. A second option takes the episodes as a starting point for role-play and group work in which the goal is to create alternative versions using more conventional strategies. Again such work raises awareness of the way in which language shifts to reflect shifts in context.

In a survey of research into the effects of instruction in second language pragmatics, Kasper and Rose (2002: 258) conclude that pragmatics is teachable and that instruction is clearly beneficial, outpacing the effects of exposure alone. Furthermore, learners provided with metapragmatic information outperform those without this information (Kasper and Rose 2002: 268). More specifically the authors note that:

Teachers can explicitly model and guide students in their use of target practices, engage students in awareness-raising activities of L2 pragmatics, and provide feedback on students' productions. Peer activities enable students to collaboratively work on tasks and support each other's development of pragmatic ability through using the target language and metapragmatic discussion.

(Kasper and Rose 2002: 233)

Ellis (1999) also argues for an approach to instruction which focuses on awareness rather than performance. 'Awareness' in this case refers both to 'forming some kind of explicit representation of a target form' (Ellis 1999: 15), and to noticing formal qualities of the input. While Ellis is referring here to grammar instruction, adapting strategies developed for instruction in grammar to instruction in pragmatics and sociopragmatics is a widespread practice. In their extensive discussion of this topic, Kasper and Rose (2002: 259-68) conclude that there is considerable support for the role of explicit instruction and noticing in sociopragmatic development. The following sociopragmatic features are, in my opinion, candidates for the awarenessraising approach proposed by Ellis:

- the functional complexity of talk - one form often has many layers of meaning, and a form which causes raised eyebrows in one context is perfectly acceptable in another;

- the range of discourse strategies available for expressing meaning in different contexts;

- discursive ways of being polite or impolite;

- the relationship between appropriateness and politeness in different contexts;

- the range of strategies available for boosting and softening the strength of a speech act; and

- the different strengths of direct and indirect speech acts in different contexts. 
Drawing on the observations from Kasper and Rose (2002) and Ellis (1999), the following section proposes a series of tasks for using authentic workplace talk. The specific examples of tasks were developed for a workplace language class and trialled by three teachers. The tasks are:

a) awareness-raising tasks

b) interpretation tasks

c) communication practice tasks.

\section{A AWARENESS-RAISING TASKS}

Sample Task 1 ( $p$ 58) is an example of an awareness-raising task which focuses on communication strategies. It reflects the first of the two meanings of awareness proposed by Ellis (1999), that is awareness as attention to explicit knowledge. In this task, the terms 'fight, flee, flow' 5 are used as a simple rubric to represent different ways to act in face-threatening interactions. While these terms are not part of a theoretical framework of communication, the teachers using these materials found them to be a helpful tool in the teaching of strategies for managing difficult communication.

\section{B INTERPRETATIONTASKS}

Interpretation tasks reflect the second dimension of awareness proposed by Ellis, that is awareness as noticing. Interpretation tasks encourage learners to attend to and interpret sociopragmatic meaning in authentic language episodes. Interpretation and noticing can be encouraged through the use of prompt questions such as the following:

- What is the bare message?

- What other messages are being communicated?

- How are these messages being communicated (wording, tone non-verbal language)?

- What does the way people are talking to each other tell you about their relationship with each other?

- How would you interpret the [speech act/episode]?

- How does the addressee interpret the [speech act/episode]?

- How would you rate the politeness of the [speech act/episode]?

- How would you rate the appropriateness of the [speech act/episode]?

Sample Task 2 (p 58) is an example of an interpretation task in which learners use explicit knowledge acquired from Task 1 to identify the particular communication strategies used by the interlocutors in Episode 1 (p 52). 


\section{Sample Task I}

\section{Approaches to communication: Fight, Flow or Flee}

We can manage a communication problem in three ways: by fighting, flowing or fleeing.

What do these words mean? What kinds of communication style do you think each word could describe? Give an example.

Now look at the list of communication strategies below and match each strategy with one of the approaches to communication.

Fight

Flow

Flee

\section{Strategies}

Use aggressive language

Use cooperative language

Listen to others

Offer solutions

Raise your voice

Use blaming language

Use suggestions

Use polite forms

Focus on problems

Avoid eye contact

Interrupt others

Use swear word

Ask open questions

Give orders

\section{Sample Task 2}

\section{The situation}

Russell is a worker on a factory floor production team. He has been working on the same packing line for several days and is tired of this work. The quality of his work has not been very good. He wants to change to another packing line. Members of the team are regularly moved to different packing lines to give them variety in their work. Lesia, the coordinator of the team Russell works in, is reluctant to shift Russell to another line.

I Listen to the conversation between Russell and Lesia. What approaches to communication are Russell and Lesia using - fight, flow or flee? Answer by circling points somewhere on the line for Russell and for Lesia.

Fight Flow Flee

2 Read the conversation between Russell and Lesia. Underline examples of fight, flow or flee strategies.

3 Find examples of language that Russell and Lesia use to boost their meaning. 


\section{COMMUNICATION PRACTICE TASKS}

Role-play engages learners in a communication practice which requires sensitivity to sociopragmatic dimensions of language. Sample Task 3 is a simple role-play prompt based again on Episode 1. To highlight sociopragmatic dimensions of language in this role-play, pairs of role-play cards can be produced to vary the status, power and/or social distance between Russell and Lesia. Different pairs of learners can then be allocated these cards and asked to prepare a role-play based on the relationship they have been given. Role-plays are then compared to encourage discussion of the ways in which language is shaped by contextual factors.

\section{Sample Task 3}

\section{Role-play}

I Working in pairs, prepare a conversation between Russell and Lesia in which Russell uses Flow strategies to overcome Lesia's reluctance to agree to his request.

Alternatively, learners can be presented with the first few moves of an episode along with background information. They are then asked to work in pairs to complete the episode. Their versions are discussed and then compared against the original episode.

Together, the three task types offer a varied but integrated approach to using authentic talk in language instruction for the workplace. Awarenessraising tasks assist learners to interpret pragmatic meanings in authentic talk. Learners are then well placed to appropriate this knowledge for their own communicative ends.

\section{Conclusion}

Our research into a wide range of workplaces indicates that the sociolinguistic and socio-pragmatic demands of integrating into a new workplace are often very daunting. Learning ways of interacting which are appropriate and normal in a workplace is an important aspect of fitting in and becoming an integrated member of the workplace as a community of practice. Sociopragmatic competence is an often underestimated aspect of workplace success.

Even those born and brought up in an English-speaking speech community may find the process of learning how to do things appropriately with words in the workplace very challenging. Fitting into the workplace involves learning the sociolinguistic and sociopragmatic rules of expression which are particular to the specific community of practice one is joining. Managing workplace discourse, knowing how to make a complaint appropriately, how to make a joke, how to disagree without causing offence, and how to refuse effectively 
are all examples of areas which can present pitfalls to people from cultures with different norms from those of their co-workers.

Our research strongly supports an approach to teaching and training that is firmly based in the workplaces in which people are working. Our analyses of the complexities of authentic workplace interaction suggest that teaching materials need to move beyond formulaic phrases and artificially constructed textbook dialogues, which bear little relation to genuine workplace talk. The evidence surveyed in this paper indicates that distinctive ways of doing things develop in particular communities of practice. Our experience suggests that teachers, therefore, need to make use of multi-media resources for work-oriented communications skills courses that are based on authentic interaction in the organisations and factories in which their students will be working. In sum, our research provides evidence that the expensive and complex business of collecting and analysing authentic workplace interaction has worthwhile practical outcomes for those engaged in preparing people for the communicative demands of the workplace. 


\section{Appendix}

TRANSCRIPTION CONVENTIONS

All names are pseudonyms.

[laughs]

[drawls]

$\ldots / \ldots . . .1 \ldots$

$\ldots / \ldots \ldots . . .$.

$+$

(3)

(hello)

?

[voc] paralinguistic or descriptive features in square brackets

indicates the scope of the paralinguistic feature it accompanies

simultaneous speech

pause of up to one second

pause of 3 seconds

transcriber's best guess at an unclear utterance

rising or question intonation

untranscribable noises 


\section{NOTES}

1 An earlier version of this paper was presented at The 13th World Congress of Applied Linguistics (AILA), Singapore, December 2002. Face-threatening talk on the factory floor: Implications for intercultural communication. Newton, J., N. Daly, J. Holmes \& M. Stubbe.

2 The LWP website can be found at http://www.vuw.ac.nz/lals/lwp

3 Source: Statistics New Zealand, 2001 Census, Table 18. Retrieved from www.stats.govt.nz/tablefinder

4 A fuller analysis of this episode can be found in Daly, Holmes, Newton and Stubbe (in press).

5 The term 'fight-flight response' originates from biology (see, for example, Jansen, Nguyen, Karpitskiy, Mettenleiter and Loewy 1995) and has found its way into a wide range of disciplines including cultural anthropology, communications training, and psychotherapy. In therapeutic and communication training contexts, the term 'flow' is often added. Note that 'flight' is changed in the materials to 'flee' in order to distinguish it from 'fight'.

\section{REFERENCES}

Besson, A. L., Roloff, M. E., \& Paulson, G. D. (1998). Preserving face in refusal situations. Communication Research, 25, 183-199.

Blum-Kulka, S., House, J., \& Kasper, G. (Eds.). (1989). Cross-cultural pragmatics: Requests and apologies. Norwood, NJ: Ablex.

Boxer, D. (1993). Social distance and speech behavior: The case of indirect complaints. Journal of Pragmatics, 19, 103-125.

Breen, M. P. (1985). Authenticity in the language classroom. Applied Linguistics, 6(1), $60-70$.

Brown, P., \& Levinson, S. C. (1987). Politeness. Some universals in language usage. Cambridge: Cambridge University Press.

Burns, A., Gollin, S., \& Joyce, H. (1997). Authentic spoken texts in the language classroom. Prospect, 12(2), 72-86.

Carter, R. (1998). Orders of reality: CANCODE, communication, and culture. ELT Journal, 52(1), 43-56.

Clyne, M. (1994). Intercultural communication at work. Cultural values in discourse. Cambridge: Cambridge University Press.

Coates, J. (1996). Women talk. Conversations between women friends. Oxford: Blackwell.

Cook, G. (1997). Language play, language learning. ELT Journal, 51(3), 224-231.

Cook-Gumperz, J. (1994). Cooperation, collaboration and pleasure in work. In A. Di Luzio, S. Günthner \& F. Orletti (Eds.), Culture in communication (pp. 117-139). Amsterdam: John Benjamins.

Daly, N., Holmes, J., Newton, J., \& Stubbe, M. (in press). Expletives as solidarity signals in FTAs on the factory floor. Journal of Pragmatics. 
Day, R. (2003). Authentic materials: A wolf in sheep's clothing. Guidelines, 25(2), 21-24.

Eelen, G. (2001). A critique of politeness theories. Manchester: St Jerome.

Ellis, R. (1999). The place of grammar instruction in the second/foreign language curriculum. New Zealand Studies in Applied Linguistics, 5, 1-21.

Gass, S., \& Neu, J. (Eds.). (1996). Speech acts across cultures: Challenges to communication in a second language. Berlin/New York: Mouton de Gruyter.

Goffman, E. (1967). Interaction ritual: Essays on face to face behaviour. New York: Anchor Books.

Hay, J. (1994). Jocular abuse patterns in mixed-group interactions. Wellington Working Papers in Linguistics, 6, 26-55.

Holmes, J., \& Meyerhoff, M. (1999). The community of practice: Theories and methodologies in language and gender research. Language in Society, 28(2), 173-183.

Holmes, J., \& Stubbe, M. (2003). Power and politeness in the workplace: A sociolinguistic analysis of talk at work. London: Longman.

Houck, N., \& Gass, S. M. (1996). Non-native refusals: A methodological perspective. In S. M. Gass \& J. Neu (Eds.), Speech acts across cultures (pp. 46-63). New York: Mouton de Gruyter.

Hughes, S. (1992). Expletives of lower working-class women. Language in Society, 21, 291-303.

Jansen, A. S. P., Nguyen, X. V., Karpitskiy, V., Mettenleiter, T. C., \& Loewy, A. D. (1995). Central command neurons of the sympathetic nervous system: Basis of the fight-or-flight response. Science, 270, 644-646.

Kasper, G., \& Blum-Kulka, S. (Eds.). (1993). Interlanguage pragmatics. Oxford: Oxford University Press.

Kasper, G., \& Dahl, M. (1991). Research methods in interlanguage pragmatics. Studies in Second Language Acquisition, 13, 215-247.

Kasper, G., \& Rose, K. R. (2002). Pragmatic development in a second language. Language Learning, 52, Supplement 1, 1-352.

Kennedy, G. (2003). Amplifier collocations in the British National Corpus: Implications for English language teaching. TESOL Quarterly, 37(3), 467-489.

Kiesling, S. (2001). 'Now I gotta watch what I say': Shifting constructions of gender and dominance in discourse. Journal of Linguistic Anthropology, 11(2), 250-73.

Kuiper, K. (1991). Sporting formulae in New Zealand English: Two models of male solidarity. In J. Cheshire (Ed.), English around the world. Sociolinguistics perspectives (pp. 200-209). Cambridge: Cambridge University Press.

Leidner, R. (1993). Fast food, fast talk: Service work and the routinisation of everyday life. Berkeley: University of California Press.

MacDonald, M., Badger, R., \& White, G. (2000). The real thing?: Authenticity and academic listening. English for Specific Purposes, 19, 253-267.

Nation, I. S. P., \& Wang, K. (1999). Graded readers and vocabulary. Reading in a Foreign Language, 12, 255-380. 
Roberts, M. (1999, November). English as a second language in the workplace. Paper presented at NZ Linguistics Society Conference, Palmerston North, New Zealand.

Sinclair, J. (Ed.). (1987). Collins COBUILD English language dictionary. London: Collins.

Stubbe, M. (2000). Talk that works: Evaluating communication in a factory production team. New Zealand English Journal, 14, 55-65.

Stubbe, M. (2001). From office to production line: Collecting data for the Wellington Language in the Workplace Project. Language in the Workplace Occasional Papers, 2. Retrieved February 10, 2004, from Language in the Workplace website: http://www.vuw.ac.nz/lals/lwp

Sunaoshi, Y. (1999). Collaboration on reaching understanding: Interactions and negotiations in Japanese manufacturing plants in the US. Unpublished PhD thesis, University of Texas at Austin, Austin, USA.

Trosberg, A. (1995). Interlanguage pragmatics. Berlin: Mouton de Gruyter.

Widdowson, H. G. (1978). Teaching language as communication. Oxford: Oxford University Press.

Willing, K. (1992). Talking it through. Clarification and problem-solving in professional work. Sydney: Macquarie University. 